\title{
Cyclic Alternating Pattern in Obstructive Sleep Apnea Patients with versus without Excessive Sleepiness
}

\author{
Selda Korkmaz $\mathbb{D}^{1},{ }^{1}$ Nedime Tugce Bilecenoglu, ${ }^{2}$ Murat Aksu, $^{3}$ and Tahir Kurtulus Yoldas ${ }^{4}$ \\ ${ }^{1}$ Department of Neurology, Istanbul Aydin University, Faculty of Medicine, Istanbul, Turkey \\ ${ }^{2}$ Department of Neurology, Acibadem Kayseri Hospital, Kayseri, Turkey \\ ${ }^{3}$ Department of Neurology, Acibadem Kayseri Hospital, Acibadem University Faculty of Medicine, Istanbul, Turkey \\ ${ }^{4}$ Department of Neurology, Ankara Training and Research Hospital, Ankara, Turkey
}

Correspondence should be addressed to Selda Korkmaz; korkmazs78@gmail.com

Received 6 November 2017; Accepted 10 April 2018; Published 16 May 2018

Academic Editor: Liborio Parrino

Copyright (C) 2018 Selda Korkmaz et al. This is an open access article distributed under the Creative Commons Attribution License, which permits unrestricted use, distribution, and reproduction in any medium, provided the original work is properly cited.

\begin{abstract}
Background. One of the main hypotheses on the development of daytime sleepiness (ES) is increased arousal in obstructive sleep apnea (OSA). Cyclic alternating pattern (CAP) is considered to be the main expression of sleep microstructure rather than arousal. Therefore, we aimed to investigate whether there is any difference between OSA patients with versus without ES in terms of the parameters of sleep macro- and microstructure and which variables are associated with Epworth Sleepiness Scale (ESS) score. Methods. Thirty-eight male patients with moderate to severe OSA were divided into two subgroups by having been used to ESS as ES or non-ES. Results. There was no difference between two groups in clinical characteristics and macrostructure parameters of sleep. However, ES group had significantly higher CAP rate, CAP duration, number of CAP cycles, and duration and rate of the subtypes A2 ( $p=0.033,0.019,0.013$, and 0.019 , respectively) and lower mean phase B duration $(p=0.028)$ compared with non-ES group. In correlation analysis, ESS score was not correlated with any CAP measure. Conclusions. OSA patients with ES have increased CAP measures rather than those without ES.
\end{abstract}

\section{Introduction}

Obstructive sleep apnea (OSA) is the most common sleep related breathing disorder and characterized by complete or partial repetitive interruptions of airflow during sleep. Its prevalence was found $2 \%$ in women and $4 \%$ in men but, nowadays, possibly higher [1]. Daytime sleepiness (ES) has been considered one of the cardinal symptoms of OSA [2], but the data about the prevalence and underlying pathophysiological mechanism of ES in patients with OSA are controversial. Several studies showed that many OSA patients experience ES whereas the other studies did not [3-7]. This discrepancy can result from differences among studies in study design, statistical methodology, and tools used to evaluate ES. In those studies, many factors including sleep fragmentation, hypoxemia, and obesity have been proposed as main determinants of ES in OSA patients [8-12].

Repetitive transient cortical EEG activities occurring as a response to internal or external stimuli during sleep are a physiologic event, but an enhancement of these activities results in disruption in normal sleep architecture. Although arousal is defined as a marker of sleep disruption, each epoch encompasses several short-timed transient events not meeting diagnostic criteria of arousal. Detection and analysis of them are called cyclic alternating pattern (CAP) and it is considered to be the main expression of sleep microstructure [13]. As a marker of sleep instability, CAP describes a physiological oscillating state involving cerebral activities, autonomic functions, and behavior features. High amounts of CAP rate indicate that one or more factors interfere with sleep consolidation. Several studies have shown that sleep disorders such as OSA, PLM, and insomnia have increased CAP measures [14-16]. Furthermore, this enhancement has been dramatically reduced by CPAP titration in patients with OSA [17].

The aim of present study is to investigate whether there is any difference between OSA patients with and without ES in terms of the parameters of sleep macro- and microstructure 
and which variables are associated with Epworth Sleepiness Scale (ESS) score in OSA patients with ES. To our knowledge, CAP and its association with ES in OSA patients have not been previously investigated.

\section{Method}

2.1. Subjects. The study was conducted at the sleep units of three different centers, approved by the institutional ethical committee, and carried out in accordance with the principles of the Helsinki Declaration.

38 male patients with OSA were retrospectively recruited from among 478 patients who underwent polysomnography (PSG) at the sleep laboratory. OSA was diagnosed according to the International Classification of Sleep Disorders II. The inclusion criteria of the study were (1) age 40 to 60 years; (2) male gender; (3) AHI > 15; (4) PLMI < 5; (5) absence of psychiatric and neurologic disorders such as depression and stroke; (6) absence of another sleep disorder such as narcolepsy, insomnia, and RLS; (7) use of drug affecting the sleep structure. 38 OSA patients meeting inclusion criteria were divided into two subgroups as ES and non-ES. Baseline clinical characteristics and polysomnographic variables indicating macro- and microstructure of sleep of these 38 patients were compared between patients with and without ES. Daytime sleepiness was diagnosed in the presence of an Epworth Sleepiness Scale score (ESS) $>10$.

2.2. Video Polysomnography. A full night PSG recording was performed by using a computerized recording system $\left(\right.$ Embla $^{\circledR}$ RemLogic $^{\mathrm{TM}}$ ) consisting of (1) sleep stage scoring through six channel electroencephalography (EEG) (F4-M1, C4-M1, O4-M1, F3-M2, C3-M2, O3-M2), two channel electrooculography (EOG), and one channel electromyography (EMG); (2) respiratory scoring through a thermistor as well as a nasal pressure sensor for apnea-hypopnea detection, piezocrystal effort belts for thoraco-abdominal movement detection, and a pulse-oximeter; (3) two-lead electrocardiogram (ECG); and (4) leg movement scoring through bilateral tibial EMG and a body position detector.

2.3. Analysis of Sleep Macrostructure. Sleep was manually scored in 30-s epochs according to the criteria of the American Academy of Sleep Medicine (AASM) [18]. Sleep stages were scored as W (wake), N1 (stage 1 sleep), N2 (stage 2 sleep), N3 (stage 3 sleep-SWS), and R (rapid eye movement (REM) sleep). The PSG parameters of sleep macrostructure consisted of the following: (1) sleep scoring data: total sleep time (TST; in minutes), sleep latency (SL; lights out to first epoch of any sleep in minutes), sleep efficiency ([TST/total recording time] $\times 100$ ), wake after sleep onset (WASO; stage $\mathrm{W}$ during total recording time, minus $\mathrm{SL}$, in minutes), duration of each stage, percent of TST in each stage (time in each stage/TST), and stage REM latency (sleep onset to first epoch of stage REM in minutes); (2) respiratory events: apnea-hypopnea index (AHI; total number of apneas and hypopneas $\times 60 / \mathrm{TST})$, lowest $\mathrm{O} 2$ saturation $\left(\min \mathrm{SpO}_{2}\right)$, and mean nocturnal oxygen saturation (mean $\mathrm{SpO}_{2}$ ); apnea was defined as a drop in the peak thermal sensor excursion by $\geq 90 \%$ of baseline lasting at least 10 seconds accompanied by respiratory effort movement. Hypopnea was defined as nasal pressure signal excursions drop by $\geq 30 \%$ of baseline with $\geq 4 \%$ desaturation from pre-event baseline, or $\geq 50 \%$ of baseline with $\geq 3 \%$ desaturation from pre-event baseline or the event is associated with arousal, associated with respiratory effort; (3) movement events: periodic leg movements of sleep (PLMS) index (PLMI; number of PLMS $\times 60 / \mathrm{TST}$ ) according to the AASM criteria. The data were scored by a sleep medicine specialist who was masked to the status of subjects.

\subsection{The Analysis of Sleep Microstructure}

2.4.1. Arousal Analysis. Arousal was scored according to AASM rules [19]. Arousal was defined as an abrupt shift in EEG frequency, including alpha, theta, and/or frequencies higher than $16 \mathrm{~Hz}$ (but not spindles) lasting at least $3 \mathrm{~s}$, with at least $10 \mathrm{~s}$ of stable sleep preceding the change. Scoring an arousal in REM sleep mandated an additional increase in chin EMG tone for at least $1 \mathrm{~s}$. Complete awakening from sleep was not counted as arousal. An arousal could be accompanied by an increase in EMG activity, heart rate, and/or body movements.

2.4.2. CAP Analysis. In the present study, CAP was scored according to currently accepted criteria [20]. CAP is described as a periodic EEG activity occurring during NREM sleep and characterized by repeated sequences of transient events which recurs at intervals up to 2 minutes. These sequences are composed of a succession of CAP cycles comprising a phase $\mathrm{A}$ and the following phase $\mathrm{B}$ which is the background EEG activity separating two consecutive phases A. Phase A activities can be classified into three subtypes. Subtype A1 is predominantly composed of slow waves while subtype A3 contains fast EEG activities. Subtype A2 is a combination of both.

All CAP sequences begin with a phase A and end with a phase B. Each phase of CAP may vary from 2 to $60 \mathrm{~s}$ in duration. Accordingly, a phase A is scored within a CAP sequence only if it precedes and/or is followed by another phase $A$ in the temporal range of 2-60s. If there were three consecutive A phases followed by a non-CAP condition, the CAP sequence was stopped at the end of the second Bphase and the third A phase A was quantified as non-CAP. A continuous NREM sleep EEG pattern without any phase A for more than $60 \mathrm{~s}$ is scored as non-CAP. Isolated A phases, not tied into CAP sequences, were also included in non-CAP periods. Based on these criteria, a sample of CAP sequence scored in the current study was presented in Figure 1.

The following CAP variables were measured in the present study: CAP rate (percentage of total NREM sleep time occupied by CAP sequences); percentage and duration of each A phase subtype; A1, A2, and A3 index; number of phases A1, A2, or A3 per hour of NREM sleep; number and duration of CAP cycle; and number and duration of $\mathrm{B}$ phases. All these variables were scored manually by the sleep specialist blinded to subject identity. 
TABLE 1: Comparison of clinical characteristics and ESS score in OSA patients with and without ES (ES versus non-ES).

\begin{tabular}{lccr}
\hline & ES $(n=10)$ & Non-ES $(n=28)$ & $p$ value \\
\hline Age (years) & $55.55(4.43)$ & $53.94(4.52)$ & 0.713 \\
Weight $(\mathrm{kg})$ & $87.5(14.5)$ & $96.5(21.68)$ & 0.205 \\
Height $(\mathrm{cm})$ & $175.8(7.74)$ & $178.86(7.41)$ & 0.276 \\
BMI $\left(\mathrm{kg} / \mathrm{m}^{2}\right)$ & $28.7(2.77)$ & $28.85(7.53)$ & 0.757 \\
ESS score & $12(2.25)$ & $7.5(4.75)$ & $<\mathbf{0 0 0 1}$ \\
\hline
\end{tabular}

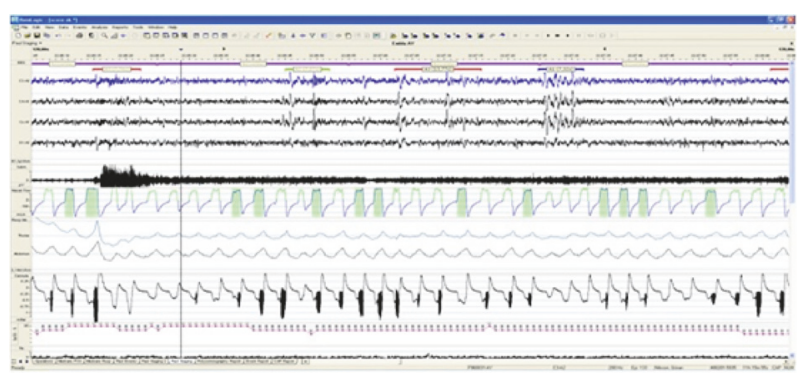

FIGURE 1: A sample of CAP sequence in the study group.

2.5. Epworth Sleepiness Scale (ESS). The ESS is an eight-item questionnaire that is used to assess the severity of daytime sleepiness in various situations [21]. The patient is required to rate his or her likelihood of sleepiness from 0 to 3 for each question. The items are as follows: (1) sitting and reading; (2) watching television; (3) sitting inactive in a public place (e.g., a theater or a meeting); (4) as a passenger in a car for an hour without a break; (5) lying down to rest in the afternoon when circumstances permit; (6) sitting and talking to someone; (7) sitting quietly after lunch without alcohol; and (8) in a car, while stopped for a few minutes in traffic. The total ESS score ranges from 0 to 24 .

The patient group was divided into two subgroups as ES, which had a score of higher than 10, or non-ES, which had a score of equal to or lower than 10 .

2.6. Statistics. All variables were examined by normality test prior to analysis. Normally distributed variables (including age, height, TST, WASO, the duration and rate of N2, N3, and REM, the number and index of arousal, CAP rate, mean A and $\mathrm{B}$ phases, the duration and rate of $\mathrm{A} 1$ subtype, the rate of $\mathrm{A} 2$ and $\mathrm{A} 3$ subtypes, and $\mathrm{A} 2$ and $\mathrm{A} 3$ index) were expressed as mean \pm standard deviation and analyzed by two independent Student's $t$-tests for examining the differences of means of different variables between the two patient subgroups (ES and non-ES). Then, skewed data (including weight, BMI, ESS score, SE, SL, the duration and rate of $\mathrm{N} 1$, the mean and lowest $\mathrm{O}_{2}$ saturation, AHI, CAP duration, the number of CAP cycles, the duration of A2 and A3 subtypes, and A1 index) were expressed as median (interquartile range), and Mann-Whitney $U$ nonparametric test was applied to examine differences between groups. Correlation analyses were performed using Spearman's correlation test. A $p$ value less than 0.05 was accepted as statistically significant.

\section{Results}

Baseline clinical characteristics and ESS score of study group are presented in Table 1 . There was no significant difference between groups in age, height, weight, and BMI. ESS score was significantly higher in ES group than non-ES group $(p \lesssim$ 0001).

There was no difference between groups in the macrostructural parameters of sleep. The comparison of the parameters of sleep macrostructure of patients with and without ES was summarized in Table 2. Regarding sleep microstructure parameters, there was no difference between groups in the number of arousal, arousal index, mean phase A duration, and the duration and rate of the subtypes $\mathrm{Al}$ and A3. However, CAP rate, CAP duration, the number of CAP cycles, and the duration and rate of the subtypes A2 were found significantly higher in ES group than non-ES group ( $p=0.033,0.019,0.013$, and 0.019 , respectively). Conversely, mean phase $\mathrm{B}$ duration was lower in ES group than non-ES group $(p=0.028)$. All parameters of sleep microstructure were summarized in Table 3.

In correlation analysis, ESS score was significantly negatively correlated with TST, N3 duration, and the duration and rate of REM in ES group $(r=-0.763,-0.731,-0.826,-0.275$ and $-0.829 ; p=0.01,0.016,0.003$, and 0.003 , respectively) whereas ESS score was significantly positively correlated with arousal index $(r=0.756, p=0.011)$ (Figures 2 and 3). Nevertheless, there was no correlation between ESS score and the parameters of CAP. Spearman's Correlation Coefficients between ESS score and the parameters of sleep architecture in ES group were presented in Table 4. Any correlation was not observed in non-ES group.

\section{Discussion}

Up to now, several studies proposed that ES is associated with some clinical parameters and the variables of conventional PSG $[6,7,10,11,22-24]$ whereas other studies did not confirm these data $[8,25,26]$. In these studies, OSA patients with ES have had higher AHI, TST, arousal index, and BMI and lower oxygen saturation, but lower N3 and REM duration compared to those without ES. We did not observe any difference between two groups in terms of the parameters of sleep macrostructure defined by conventional PSG scoring and clinical characteristics similar to several previous studies. As a result, ES is not explained by only clinical and/or conventional PSG parameters.

Respiratory events in OSA show a cyclic pattern as a cessation and resumption of breathing for certain duration, 
TABLE 2: Comparison of parameters of sleep macrostructure in OSA patients with and without ES (ES versus non-ES).

\begin{tabular}{|c|c|c|c|}
\hline & $\mathrm{ES}(n=10)$ & Non-ES $(n=28)$ & $p$ value \\
\hline TST, min & $388.94(32.86)$ & $365.66(77)$ & 0.202 \\
\hline SE & $74.1(2.17)$ & $74.5(17.42)$ & 0.708 \\
\hline SL & $12(15.88)$ & $9(8.9)$ & 0.660 \\
\hline WASO & $130.48(24.57)$ & $126.56(65.97)$ & 0.791 \\
\hline N1 duration, min & $62(23)$ & $69(62.25)$ & 0.883 \\
\hline N1, (\%) & $16.8(4.5)$ & $20.55(15.13)$ & 0.590 \\
\hline $\mathrm{N} 2$ duration, $\min$ & $196.94(47.43)$ & $199.39(57.82)$ & 0.905 \\
\hline $\mathrm{N} 2,(\%)$ & $50.62(12.04)$ & $53.97(8.18)$ & 0.335 \\
\hline N3 duration, min & $56.75(36.67)$ & $42.27(31.4)$ & 0.239 \\
\hline N3, (\%) & $14.36(8.97)$ & $11.42(8.21)$ & 0.349 \\
\hline REM duration, min & $56.65(24.34)$ & $45.68(22.27)$ & 0.200 \\
\hline REM, (\%) & $14.33(5.56)$ & $12.31(5.48)$ & 0.326 \\
\hline Mean $\mathrm{O}_{2}$ sat & $94(2.55)$ & $93.5(2.17)$ & 0.257 \\
\hline Lowest $\mathrm{O}_{2}$ sat & $84(5)$ & $80.5(11.75)$ & 0.503 \\
\hline $\mathrm{AHI}$ & $34.85(46.35)$ & $32.8(32)$ & 0.757 \\
\hline
\end{tabular}

TABLE 3: Comparison of parameters of sleep microstructure in OSA patients with and without ES (ES versus non-ES).

\begin{tabular}{|c|c|c|c|}
\hline & $\mathrm{ES}(n=10)$ & Non-ES $(n=28)$ & $p$ value \\
\hline The number of arousal & $216.2(73.25)$ & $207.5(117.19)$ & 0.828 \\
\hline Arousal index & $36.4(18.04)$ & $35.05(16.85)$ & 0.834 \\
\hline CAP duration, min & $212.15(70.88)$ & $162.9(99.33)$ & 0.019 \\
\hline $\begin{array}{l}\text { CAP rate }(\%) \\
=\mathrm{CAP}(\min ) / \mathrm{NREM}(\min ) \times 100\end{array}$ & $65.98(11.53)$ & $53.93(15.72)$ & 0.033 \\
\hline The number of CAP cycles & $375.5(165.5)$ & $293(130.25)$ & 0.013 \\
\hline Mean phase A duration, min & $16.79(1.72)$ & $16.12(2.11)$ & 0.373 \\
\hline Mean phase $\mathrm{B}$ duration, min & $17.41(2.73)$ & $20.22(3.49)$ & 0.028 \\
\hline Subtype Al duration, min & $29.53(26.76)$ & $21.25(19.17)$ & 0.299 \\
\hline Subtype A1 (\%) & $8.93(7.87)$ & $6.38(5.39)$ & 0.265 \\
\hline $\begin{array}{l}\text { Subtype A1 index } \\
\text { (The number of A1/NREM hours) }\end{array}$ & $8.6(7.93)$ & $3.5(8.4)$ & 0.070 \\
\hline Subtype A2 duration, min & $49.35(33.1)$ & $21.9(25.7)$ & 0.019 \\
\hline Subtype A2 (\%) & $15.17(6.35)$ & $9.69(6.98)$ & 0.036 \\
\hline $\begin{array}{l}\text { Subtype A2 index } \\
\text { (The number of A2/NREM hours) }\end{array}$ & $13.95(9.82)$ & $12.49(8.62)$ & 0.661 \\
\hline Subtype A3 duration, min & $145.95(40.1)$ & $113.05(38)$ & 0.051 \\
\hline Subtype A3 (\%) & $41.9(6.02)$ & $37.85(11.4)$ & 0.169 \\
\hline $\begin{array}{l}\text { Subtype A3 index } \\
\text { (The number of A3/NREM hours) }\end{array}$ & $38.51(13.83)$ & $41.56(11.66)$ & 0.503 \\
\hline
\end{tabular}

and the resumption of breathing is associated with an arousal from sleep. General agreement on arousal is to be an indicator of sleep fragmentation [27]. However, periodic EEG activities during sleep may remain unexplored if standard scoring criteria exclusively are used for arousal. Therefore, CAP which is an alternative scoring system for arousal and concomitant physiologic events during sleep. Current studies have focused on sleep instability and its association with CAP. No studies have previously investigated CAP in OSA patients with versus without ES. However, only one study has demonstrated a positive correlation between CAP rate and ESS in patients with upper airway resistance syndrome as well as a reduced NREM sleep and an elevated CAP rate [28]. Our study revealed that OSA patients with ES had an elevation in CAP measures including CAP rate and duration, the number of CAP cycle, the duration and rate of subtype $\mathrm{A} 2$, and reduction in mean phase $\mathrm{B}$ compared to ones without ES whereas arousal index was not found different between groups. The finding that OSA patients with ES have increased CAP is consistent with literature data suggesting that more disruption of sleep continuity is associated with more daytime sleepiness [14]. Based on the results of current 

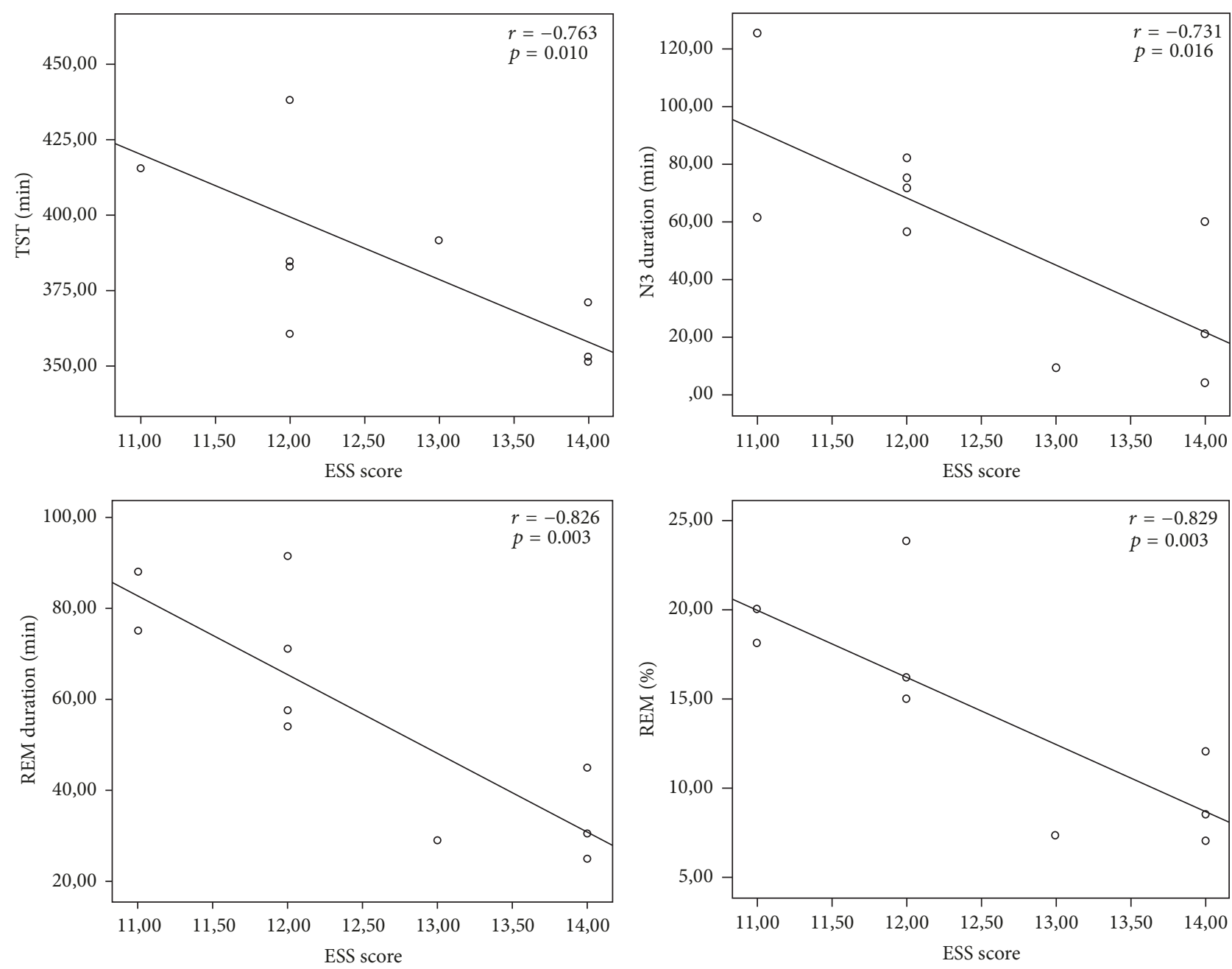

FIGURE 2: Associations between ESS score and TST and N3 duration and REM duration and REM rate.

study and previous data, further studies are needed to clarify the association between CAP and ES. When a direction of relationship between ES and CAP is revealed, CAP can be used a target in the therapy of ES or a following parameter for OSA patients with ES.

The reason why subtype $\mathrm{A} 2$ is higher than $\mathrm{A} 1$ and $\mathrm{A} 3 \mathrm{is}$ not explained in the present study. Additionally, decreased mean phase B in ES group is contradicting with previous studies reporting that mean phase B is increased in OSA patients and in a temporal relationship with respiratory events [14]. In the present study, the reduction in mean phase B seems to be protective to sleep fragmentation.

On the other hand, in correlation analysis, we found that ESS score was negatively correlated with TST, N3 duration, and the duration and rate of REM and positively correlated with arousal index in ES group whereas there was no correlation between CAP measures and ES. Additionally, any significant correlation was not observed in non ES group.

Several limitations should be considered when assessing the results of present study. First, the study sample size is quite small because of our strict inclusion criteria. Second, study groups were formed based on their ESS score. ESS reflects to individual's sleepiness subjectively and could lead to overand underestimation of ES. However, it offers advantages in terms of low cost and easy application, although MSLT is an objective neurophysiologic test measuring sleepiness. Additionally, some studies have reported that ESS has a better or equal ability to MSLT in the definition of ES [29]. Lastly, present study does not include healthy control group. The study involving healthy controls as well as OSA patients with and without ES will obtain further information about discriminating features among groups.

As a result, this present study showed that amount of CAP was increased in OSA patients with ES versus without ES. We do not know the clinical importance of the elevation of CAP in ES group. Moreover, any correlation was not found between CAP and ES. Based on the previous and the present study results, ES is a multifactorial condition and not explained by only clinical or PSG parameters including arousal, CAP. Because increased CAP rate in OSA patients with ES has been firstly documented in the present study, 
TABLE 4: Spearman's Correlation Coefficients between ESS score and the parameters of sleep architecture in ES group.

\begin{tabular}{|c|c|c|c|}
\hline & $\mathrm{ES}(n=10)$ & Non-ES $(n=28)$ & $p$ value \\
\hline The number of arousal & $216.2(73.25)$ & $207.5(117.19)$ & 0.828 \\
\hline Arousal index & $36.4(18.04)$ & $35.05(16.85)$ & 0.834 \\
\hline CAP duration, min & $212.15(70.88)$ & $162.9(99.33)$ & 0.019 \\
\hline $\begin{array}{l}\text { CAP rate }(\%) \\
=\mathrm{CAP}(\mathrm{min}) / \mathrm{NREM}(\mathrm{min}) \times 100\end{array}$ & $65.98(11.53)$ & $53.93(15.72)$ & 0.033 \\
\hline The number of CAP cycles & $375.5(165.5)$ & $293(130.25)$ & 0.013 \\
\hline Mean phase A duration, min & $16.79(1.72)$ & $16.12(2.11)$ & 0.373 \\
\hline Mean phase $B$ duration, min & $17.41(2.73)$ & $20.22(3.49)$ & 0.028 \\
\hline Subtype A1 duration, min & $29.53(26.76)$ & $21.25(19.17)$ & 0.299 \\
\hline Subtype A1 (\%) & $8.93(7.87)$ & $6.38(5.39)$ & 0.265 \\
\hline $\begin{array}{l}\text { Subtype A1 index } \\
\text { (The number of A1/NREM hours) }\end{array}$ & $8.6(7.93)$ & $3.5(8.4)$ & 0.070 \\
\hline Subtype A2 duration, min & $49.35(33.1)$ & $21.9(25.7)$ & 0.019 \\
\hline Subtype A2 (\%) & $15.17(6.35)$ & $9.69(6.98)$ & 0.036 \\
\hline $\begin{array}{l}\text { Subtype A2 index } \\
\text { (The number of A2/NREM hours) }\end{array}$ & $13.95(9.82)$ & $12.49(8.62)$ & 0.661 \\
\hline Subtype A3 duration, min & $145.95(40.1)$ & $113.05(38)$ & 0.051 \\
\hline Subtype A3 (\%) & $41.9(6.02)$ & $37.85(11.4)$ & 0.169 \\
\hline $\begin{array}{l}\text { Subtype A3 index } \\
\text { (The number of A3/NREM hours) }\end{array}$ & $38.51(13.83)$ & $41.56(11.66)$ & 0.503 \\
\hline
\end{tabular}

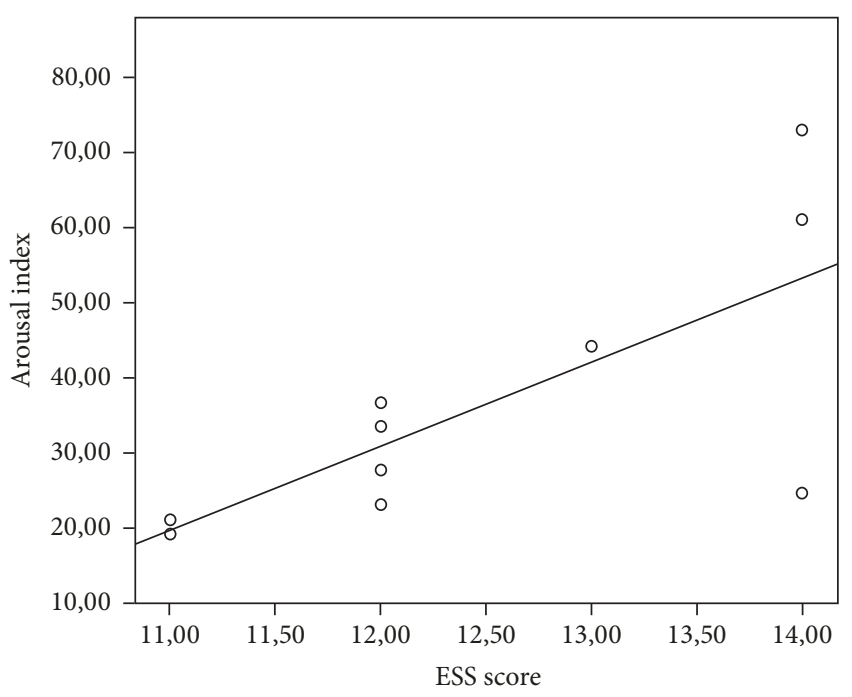

FIGURE 3: Relationship between ESS score and arousal index.

firstly, this finding should be confirmed by the future studies and then its clinical consequence should be investigated.

\section{Data Availability}

The data of study subjects were retrospectively obtained from recordings at sleep laboratory.

\section{Ethical Approval}

This retrospective cohort study was approved by ethical committee of The Turkish Ministry of Health, and with the 1964 Helsinki declaration and its later amendments or comparable ethical standards.

\section{Conflicts of Interest}

The authors declare that they have no conflicts of interest.

\section{Authors' Contributions}

Study design: All authors played a role in this stage. Data collection and statistical analysis: Selda Korkmaz and Nedime Tugce Bilecenoglu collected all data of study subjects, and data analysis was made by them. Interpretation of the results: Selda Korkmaz and Murat Aksu contributed to this stage of study. Manuscript drafting: Selda Korkmaz had a main role in this stage accompanied with editing service.

\section{Acknowledgments}

The authors thank the authors who had presented this research as a poster, whose title is The Alteration of Cyclic Alternating Pattern in Obstructive Sleep Apnea Syndrome with and without Excessive Daytime Sleepiness at Congress of American Academy of Neurology, 2015. 


\section{References}

[1] T. Young, M. Palta, J. Dempsey, J. Skatrud, S. Weber, and S. Badr, "The occurrence of sleep-disordered breathing among middleaged adults," The New England Journal of Medicine, vol. 328, no. 17, pp. 1230-1235, 1993.

[2] C. Guilleminault, J. van den Hoed, and M. M. Mitler, "Clinical overview of the sleep apnea syndromes," in Sleep Apnea Syndromes, C. Guilleminault and W. C. Dement, Eds., pp. 1-12, Alan R Liss, New York, NY, USA, 1978.

[3] H. M. Engleman and N. J. Douglas, "Sleep 4: sleepiness, cognitive function, and quality of life in obstructive sleep apnoea/ hypopnoea syndrome," Thorax, vol. 59, no. 7, pp. 618-622, 2004.

[4] C. Sauter, S. Asenbaum, R. Popovic et al., "Excessive daytime sleepiness in patients suffering from different levels of obstructive sleep apnoea syndrome," Journal of Sleep Research, vol. 9, no. 3, pp. 293-301, 2000.

[5] V. K. Kapur, C. M. Baldwin, H. E. Resnick, D. J. Gottlieb, and F. J. Nieto, "Sleepiness in patients with moderate to severe sleepdisordered breathing," SLEEP, vol. 28, no. 4, pp. 472-477, 2005.

[6] E. O. Bixler, A. N. Vgontzas, H.-M. Lin, S. L. Calhoun, A. Vela-Bueno, and A. Kales, "Excessive daytime sleepiness in a general population sample: the role of sleep apnea, age, obesity, diabetes, and depression," The Journal of Clinical Endocrinology \& Metabolism, vol. 90, no. 8, pp. 4510-4515, 2005.

[7] A. Oksenberg, E. Arons, K. Nasser, O. Shneor, H. Radwan, and D. S. Silverberg, "Severe obstructive sleep apnea: sleepy versus nonsleepy patients," The Laryngoscope, vol. 120, no. 3, pp. 643648,2010

[8] C. Guilleminault, M. Partinen, M. A. Quera-Salva, B. Hayes, W. C. Dement, and G. Nino-Murcia, "Determinants of daytime sleepiness in obstructive sleep apnea," CHEST, vol. 94, no. 1, pp. 32-37, 1988 .

[9] H. G. Colt, H. Haas, and G. B. Rich, "Hypoxemia vs sleep fragmentation as cause of excessive daytime sleepiness in obstructive sleep apnea," CHEST, vol. 100, no. 6, pp. 1542-1548, 1991.

[10] O. Mediano, A. Barcelo, M. de la Pena, D. Gozal, A. Agusti, and F. Barbe, "Daytime sleepiness and polysomnographic variables in sleep apnoea patients," European Respiratory Journal, vol. 30, no. 1, pp. 110-113, 2007.

[11] Y. Sun, Y. Ning, L. Huang et al., "Polysomnographic characteristics of daytime sleepiness in obstructive sleep apnea syndrome," Sleep and Breathing, vol. 16, no. 2, pp. 375-381, 2012.

[12] U. Seneviratne and K. Puvanendran, "Excessive daytime sleepiness in obstructive sleep apnea: prevalence, severity, and predictors," Sleep Medicine, vol. 5, no. 4, pp. 339-343, 2004.

[13] M. G. Terzano, D. Mancia, M. R. Salati, G. Costani, A. Decembrino, and L. Parrino, "The cyclic alternating pattern as a physiologic component of normal NREM sleep," SLEEP, vol. 8, no. 2, pp. 137-145, 1985.

[14] M. G. Terzano, L. Parrino, M. Boselli, M. C. Spaggiari, and G. Di Giovanni, "Polysomnographic analysis of arousal responses in obstructive sleep apnea syndrome by means of the cyclic alternating pattern," Journal of Clinical Neurophysiology, vol. 13, no. 2, pp. 145-155, 1996.

[15] L. Parrino, M. Boselli, G. P. Buccino, M. C. Spaggiari, G. Di Giovanni, and M. G. Terzano, "The cyclic alternating pattern plays a gate-control on periodic limb movements during nonrapid eye movement sleep," Journal of Clinical Neurophysiology, vol. 13, no. 4, pp. 314-323, 1996.

[16] L. Parrino, G. Milioli, F. De Paolis, A. Grassi, and M. G. Terzano, "Paradoxical insomnia: the role of CAP and arousals in sleep misperception," Sleep Medicine, vol. 10, no. 10, pp. 1139-1145, 2009.

[17] R. J. Thomas, "Cyclic alternating pattern and positive airway pressure titration,” Sleep Medicine, vol. 3, no. 4, pp. 315-322, 2002.

[18] R. B. Berry, R. Brooks, C. E. Gamaldo et al., The AASM Manual for the Scoring of Sleep and Associated Events: Rules, Terminology and Technical Specifications, American Academy of Sleep Medicine, Darien, CT, USA.

[19] M. Bonnet, D. Carley, M. Carskadon et al., "EEG arousals: scoring rules and examples: a preliminary report from the Sleep Disorders Atlas Task Force of the American Sleep Disorders Association," SLEEP, vol. 15, no. 2, pp. 173-184, 1992.

[20] M. G. Terzano, L. Parrino, A. Smerieri et al., "Atlas, rules, and recording techniques for the scoring of cyclic alternating pattern (CAP) in human sleep," Sleep Medicine, vol. 3, no. 2, pp. 187-199, 2002.

[21] M. W. Johns, "A new method for measuring daytime sleepiness: the Epworth sleepiness scale," SLEEP, vol. 14, no. 6, pp. 540-545, 1991.

[22] R. Chen, K. Xiong, Y. Lian et al., "Daytime sleepiness and its determining factors in Chinese obstructive sleep apnea patients," Sleep and Breathing, vol. 15, no. 1, pp. 129-135, 2011.

[23] M. Cao, C. Guilleminault, and C. Kushida, "Clinical features and evaluation of obstructive sleep apnea and upper airway resistance syndrome," in Principles and Practice of Sleep Medicine, M. Kryger, T. Roth, and W. Dement, Eds., pp. 12061218, Elsevier Saunders, St Louis, MO, USA, 5th edition, 2011.

[24] M. Basta, H.-M. Lin, S. Pejovic, A. Sarrigiannidis, E. O. Bixler, and A. N. Vgontzas, "Lack of regular exercise, depression, and degree of apnea are predictors of excessive daytime sleepiness in patients with sleep apnea: sex differences," Journal of Clinical Sleep Medicine, vol. 4, no. 1, pp. 19-25, 2008.

[25] N. Roure, S. Gomez, O. Mediano et al., "Daytime sleepiness and polysomnography in obstructive sleep apnea patients," Sleep Medicine, vol. 9, no. 7, pp. 727-731, 2008.

[26] L. S. Bennett, B. A. Langford, J. R. Stradling, and R. J. O. Davies, "Sleep fragmentation indices as predictors of daytime sleepiness and nCPAP response in obstructive sleep apnea," American Journal of Respiratory and Critical Care Medicine, vol. 158, no. 3, pp. 778-786, 1998.

[27] T. Roehrs, M. A. Carskadon, W. C. Dement, and T. Roth, "Daytime sleepiness and alertness," in Principles and Practice of Sleep Medicine, M. H. Kryger, T. Roth, and W. C. Dement, Eds., pp. 40-49, Philadelphia, PA, USA, 1994.

[28] C. Guilleminault, M. C. Lopes, C. C. Hagen, and A. Da Rosa, "The cyclic alternating pattern demonstrates increased sleep instability and correlates with fatigue and sleepiness in adults with upper airway resistance syndrome," SLEEP, vol. 30, no. 5, pp. 641-647, 2007.

[29] M. W. Johns, "Sensitivity and specificity of the multiple sleep latency test (MSLT), the maintenance of wakefulness test and the epworth sleepiness scale: failure of the MSLT as a gold standard," Journal of Sleep Research, vol. 9, no. 1, pp. 5-11, 2000. 


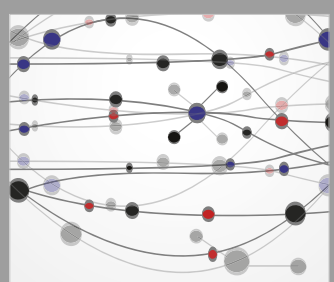

The Scientific World Journal
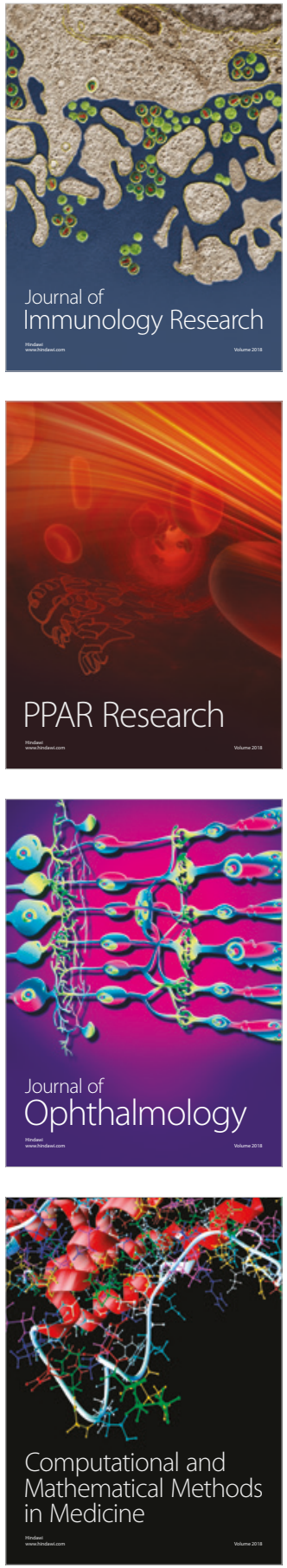

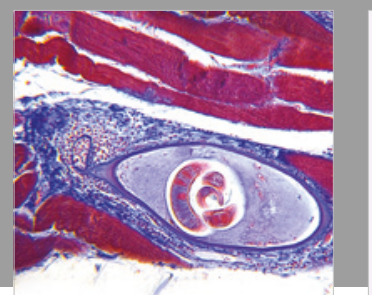

Gastroenterology Research and Practice

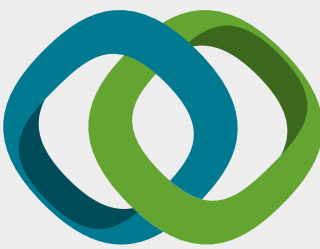

\section{Hindawi}

Submit your manuscripts at

www.hindawi.com
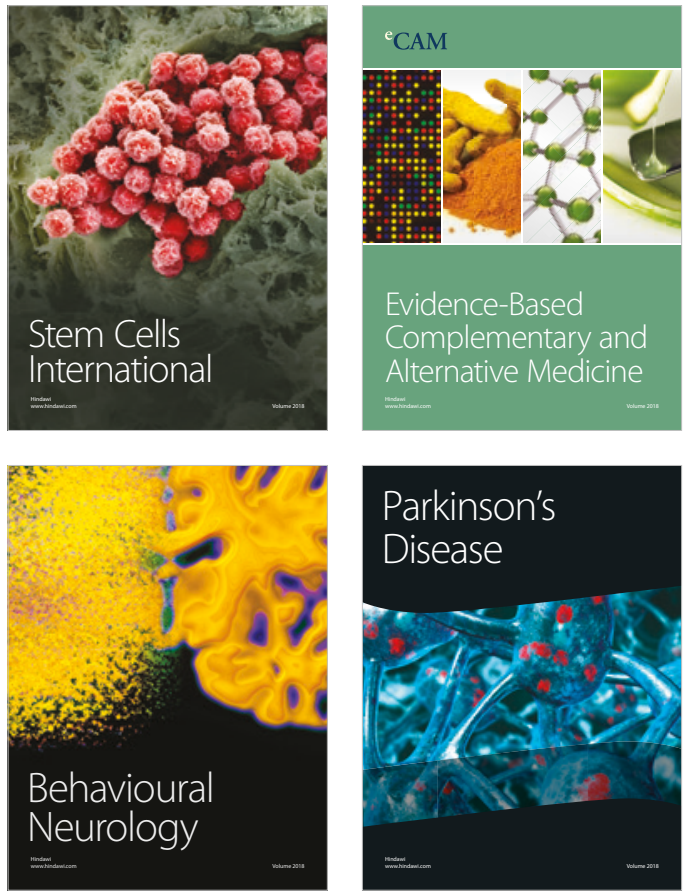

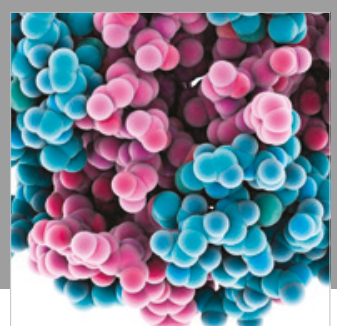

ournal of

Diabetes Research

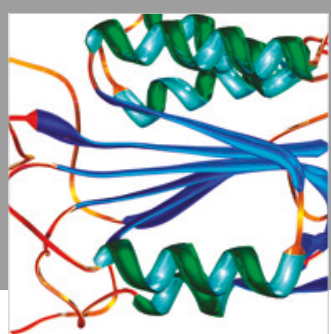

Disease Markers
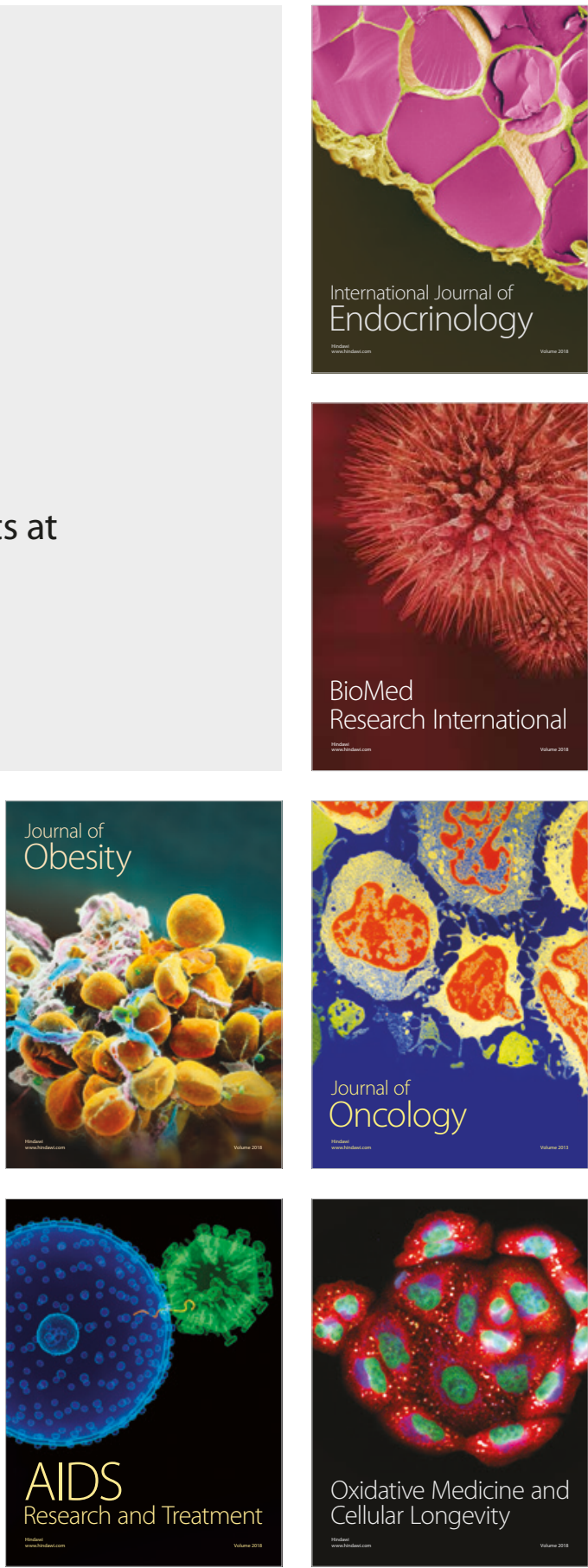